\title{
Preliminary research on the method for determination of ground motion parameters of diffuse earthquakes*
}

\author{
Jian $\mathrm{Wu}$ and Yanxiang $\mathrm{Yu}^{*}$ \\ Institute of Geophysics, China Earthquake Administration, Beijing 100081, China
}

\begin{abstract}
This paper proposes that on the basis of near-source saturation characteristic of ground motion, the peak ground motion acceleration and the acceleration response spectra of diffuse earthquakes affecting the nuclear facility site can be determined by the statistic method. In view of the problem of insufficient statistic samples due to fewer qualified strong earthquake records on the bedrock site, it also proposes that according to the features of ground motion response of the soil, the acceleration records on the soil site can be transformed into the equivalent acceleration records on rock site for a simultaneous statistic analysis together with the records on rock site. Consequently, we have obtained by this method the near-source peak acceleration and the acceleration response spectra of small and moderate earthquakes on the site that could meet the need of nuclear facility and made a comparative analysis to the results from relevant researches. This new method for determining diffuse earthquakes is only preliminarily verified in the paper and further research is needed for practical application.
\end{abstract}

Key words: diffuse earthquake; near-source; ground motion; saturation; record transformation CLC number: P315.3 $3^{+}$Document code: A

\section{Introduction}

Diffuse earthquake is a very important factor to affect the determination of design basis ground motion for nuclear facility. We have known from the definition of diffuse earthquake and the evaluation of its influence issued in the present safety guide for nuclear facilities in China, the HAD101(01), the relevant stipulations in the safety guide of International Atomic Energy Agency (IAEA) are basically used in China now. In the Evaluation of Seismic Hazards for Nuclear Power Plants (No. NS-G-3.3) included in the current version of safety guide of International Atomic Energy Organization, the diffuse earthquake is defined as the seismic activity irrelevant to the given seismogenic structure and it is generally small and moderate earthquake. It is also stipulated that in considering the ground motion influence on the nuclear facility site, the diffuse earthquake should "occur at some identified specific distance from the site, on the basis of investigations which ensure that

\footnotetext{
* Received 13 November 2009; accepted in revised form 4 January 2010; published 10 February 2010.

•Corresponding author. e-mail: yuyx@cea-igp.ac.cn

(c) The Seismological Society of China and Springer-Verlag Berlin Heidelberg 2010
}

there are no seismogenic structures within this distance", and this distance could be several or tens kilometers. However, the existence of potential seismogenic structure in this distance should only be excluded on the basis of detailed investigation, so that the possibility of earthquake occurrence in this region could be as low as being ignored. Moreover, the focal depth and the physical dimensions of the source should also be considered reasonably.

In the practical evaluation of ground motion parameters for the nuclear facility in China, it is generally accepted to carry out 1:50 000 geological investigation and fault activity discrimination in the region near the facility site to ensure that earthquake with the same magnitude as the maximum diffuse earthquake would not occur in the field within $5 \mathrm{~km}$ to the nuclear facility site. Then on the basis of statistic analysis of regional focal depth, the acceleration response spectra at the location of 5-km epicentral distance calculated with a reasonable attenuation relation can be used as the ground motion influence of diffuse earthquake on the facility site. This method was suitable under the basic condition at that time ( $\mathrm{Li}$ et al, 2005). However, it has the following deficiencies in thorough consideration: (1) Diffuse 
earthquake is defined as seismic activity that is irrelevant to the given seismogenic structure, but the abovementioned geological investigation and fault activity discrimination could only be made to the specific structures. In this respect, the possibility of small and moderate earthquakes occurring within the range of $5 \mathrm{~km}$ to the facility site could not be excluded; (2) In practice, the magnitude of the largest diffuse earthquake is usually 5.0 and 5.5 or 6.0 in few cases. However, this kind of small and moderate earthquake generally has no surface rupture, so the occurrence of this kind of earthquake cannot be discovered by means of surface geological investigation. Consequently, the possibility of this kind of earthquake occurrence cannot be predicted or excluded merely by the results from surface geological investigation; (3) In determining the ground motion attenuation relationship by statistic regression method, ground motion acceleration records are used, but most of them are the records of moderate earthquakes in the medium distance. However, the influence of diffuse earthquake on the nuclear facility site is mainly from the ground motion in the near field or even at the epicenter. Therefore, the ground motion influence of diffuse earthquake calculated by this kind of attenuation relationship for the site could not fully reflect the near-source characteristics of ground motion of small and moderate earthquakes.

As a kind of seismic activity irrelevant to the given seismogenic structure, the diffuse earthquake might occur anywhere. Under the present condition of data accumulation and our understanding for diffuse earthquake occurrence, we are not able to exclude the possibility of its occurrence beneath the site. Therefore, in a conservative consideration for the ground motion of diffuse earthquake on the site, the maximum ground motion of a M5-6 earthquake at the surface of the epicentral region could be considered as its influence on the site, which can be used as one of the basic data to design basis ground motion for the nuclear facility. The method to calculate the influence of diffuse earthquake with attenuation relationship is reasonable under the condition of insufficient strong earthquake records. Now the ground motion records have been increased greatly, therefore, the principle proposed in this paper could be used to reasonably determine the influence of diffuse earthquake on the nuclear facility site directly from the records of near-source ground motion of small and moderate earthquakes by a rational statistic analysis method.

\section{Near-source saturation of ground motion}

The near-source saturation of ground motion has been discovered and studied for a long time (Campbell, 1981) and relevant research has lasted up to the present (Huo, 1989; Yu, 2002; Abrahamson and Silva, 2008; Boore and Atkinson, 2008; Campbell and Bozorgnia, 2008; Chiou and Youngs, 2008; Schmedes and Archuleta, 2008). Generally speaking, in the epicentral area or a certain range near the seismogenic fault, the increase of peak ground motion acceleration with the decrease of distance would become unobvious, or even the peak ground motion acceleration in this range would approximately be a constant. In the model of near-fault ground motion attenuation relationship, the above researchers introduced a characteristic distance value $R_{0}$ for the near-source saturation of ground motion, that is

$$
\ln a_{\mathrm{PG}} \propto \ln \left(R+R_{0}\right),
$$

where, $a_{\mathrm{PG}}$ is PGA value, and $R$ is the distance from the site to the seismogenic fault or the epicenter. The above researchers used different methods to determine $R_{0}$ value. Some of them considered that $R_{0}$ is correlative to the size of the fault rupture zone, especially to fault length for the larger shallow-focus events. Since fault rupture dimensions scale exponentially with magnitude, it would be expected that $R_{0}$ also scales exponentially with magnitude (Campbell, 1981; Huo, 1989; Yu, 2002), that is

$$
R_{0}=c_{1} \exp \left(c_{2} M\right),
$$

where, $c_{1}$ and $c_{2}$ are regression coefficients and $M$ is magnitude. For M5-6 earthquakes, the obtained $R_{0}$ are 6-12 km by Campbell (1981), 6-13 km by Huo (1989), and $10-16 \mathrm{~km}$ by $\mathrm{Yu}$ (2002), respectively. Based on the analyzed result for eight better-distributed earthquakes with different magnitudes recorded in the database compiled for the Next Generation of Ground Motion Attenuation Models (NGA) project (Chiou et al, 2006), $R_{0}$ value should be 20-29 km for M5-6 earthquakes.

The saturation characteristic of near-source ground motion enables us to use the statistics of ground motion records within the saturation zone as the ground motion influence of diffuse earthquake on the nuclear facility site. The model in equation (2) is relatively simple with a definite physical conception, which is used in the paper to determine the distance range of earthquake records for statistic analysis. According to the model in equation (2), the near-source saturation distance $R_{0}$ for M5-6 earthquakes should be several to $20 \mathrm{~km}$. According to Zhang et al (2004) and the NGA database, the fault rupture are 
about from $5 \mathrm{~km}$ to less than $25 \mathrm{~km}$ in size for $M 5-6$ earthquakes. We therefore select, on the basis of the existed research results, the ground motion records with an epicentral distance less than $10 \mathrm{~km}$ for the statistic analysis, in order to determine the mean value for the peak ground motion acceleration records of M5-6 earthquakes in near field. And the obtained results can be used as a basis in determining the influence of peak ground motion acceleration and acceleration response spectra of diffuse earthquakes on the nuclear facility site.

\section{Samples}

According to the magnitude and distance range of diffuse earthquakes determined in the above sections, the ground motion records with magnitude of 4.75-6.25 and epicentral distance of $0-10 \mathrm{~km}$ are determined for selecting statistic samples. The data are from the strong earthquake records in the NGA database compiled for next generation attenuation program of the Pacific Earthquake Engineering Research Center (PEER). All the earthquake records are divided into three parts according to magnitude; they are 4.75-5.24, 5.25-5.74 and 5.75-6.25 for the statistic samples of M5.0, M5.5 and M6.0 diffuse earthquakes, respectively.

It is stipulated in the relevant specifications for the nuclear facility in China, the engineering structure relating to nuclear safety must be located on the bedrock site with a shear wave velocity $V_{\mathrm{S} 30} \geq 700 \mathrm{~m} / \mathrm{s}$, while only two records with the magnitudes of 5.61 and 4.90 in the NGA database could meet the site condition of shear wave velocity $V_{\mathrm{S} 30}>700 \mathrm{~m} / \mathrm{s}$ for the nuclear facility. If the requirement for site condition is properly softened to $V_{\mathrm{S} 30}>500 \mathrm{~m} / \mathrm{s}, 19$ records of 18 earthquakes would be qualified for the three magnitude grades which are 4, 7, and 8 records, respectively. In this way, only a few record samples could pass the restriction for site condition, which cannot guarantee the reliability of statistic result. If the site condition is ignored, the total records would be 84 from 36 earthquakes (see the magnitude-distance distribution in Figure 1 and the catalogue of 36 earthquakes in Table 1). Therefore, it is necessary to find a suitable method in order to increase the amount of samples that could meet the required conditions.

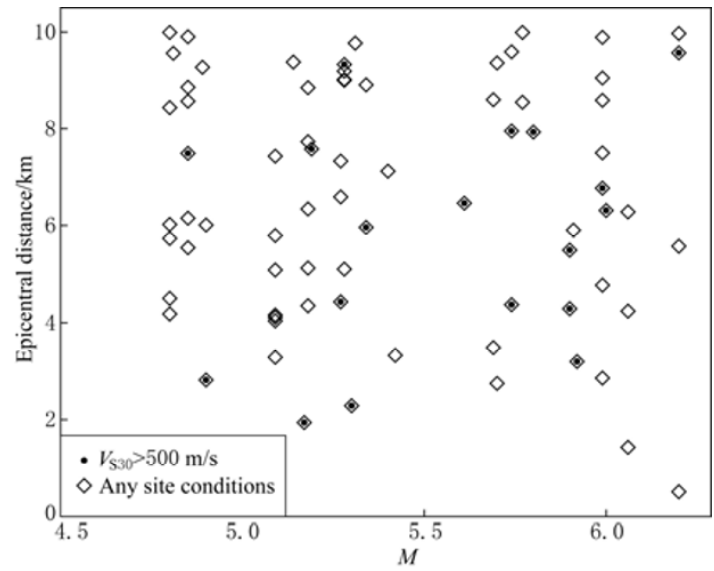

Figure 1 Magnitude versus epicentral distance distribution for record samples in different site conditions.

There are five working groups in the NGA project, therefore, five attenuation relationship models are developed independently (Abrahamson and Silva, 2008; Boore and Atkinson, 2008; Campbell and Bozorgnia, 2008; Chiou and Youngs, 2008; Idriss, 2008), which are named AS08, BA08, CB08, CY08 and I08, respectively with the first letter of the major researchers' name and the year. For different site conditions, the former four groups all use $V_{\mathrm{S} 30}$ as a variable for site correction term, but in different formations. Therefore, the site correction term can be extracted individually. We use the above four correction models to transform the ground motion records on the site of $V_{\mathrm{S} 30}<700 \mathrm{~m} / \mathrm{s}$ into the ground motion records on the site of $V_{\mathrm{S} 30}=700 \mathrm{~m} / \mathrm{s}$, which site condition is required by the nuclear facility, for a simultaneous statistic with the PGA records on the site of $V_{\mathrm{S} 30}>700 \mathrm{~m} / \mathrm{s}$. These corrected models for site condition are shown by AS08s, BA08s, CB08s and CY08s in the following chapters to correspond with the attenuation relationship models, respectively. On the basis of analysis on two earthquakes, i.e., "Chi-Chi, Taiwan-02" and "Northridge-06" in Table 1, which have more records and a more uniform distribution of stations in distance, the soil site records that have been corrected for site condition by the above method are added into the bedrock ones. It can effectively improve the distribution of records with epicentral distance. The four correction models for site condition are shown in equations (3a) to (3d).

$$
f_{5}\left(P \hat{G} A_{1100}, V_{\mathrm{S} 30}^{*}\right)= \begin{cases}a_{10} \ln \left(\frac{V_{\mathrm{S} 30}^{*}}{V_{\mathrm{LIN}}}\right)-b \ln \left(P \hat{G} A_{1100}+c\right)+b \ln \left(P \hat{G} A_{1100}+c\left(\frac{V_{\mathrm{S} 30}^{*}}{V_{\mathrm{LIN}}}\right)^{n}\right) & V_{\mathrm{S} 30}<V_{\mathrm{LIN}} \\ \left(a_{10}+b n\right) \ln \left(\frac{V_{\mathrm{S} 30}^{*}}{V_{\mathrm{LIN}}}\right) & V_{\mathrm{S} 30} \geq V_{\mathrm{LIN}}\end{cases}
$$




$$
\begin{aligned}
& F_{\mathrm{s}}=b_{\mathrm{LIN}} \ln \left(V_{\mathrm{S} 30} / V_{\mathrm{ref}}\right)+\left\{\begin{array}{lc}
b_{n l} \ln \left(p g a \_l o w / 0.1\right) & p g a 4 n l \leq a_{1} \\
b_{n l} \ln \left(p g a \_l o w / 0.1\right)+c\left[\ln \left(p g a 4 n l / a_{1}\right)\right]^{2}+d\left[\ln \left(p g a 4 n l / a_{1}\right)\right]^{3} \\
b_{n l} \ln (p g a 4 n l / 0.1) & a_{1}<p g a 4 n l \leq a_{2} \\
& a_{2}<p g a 4 n l
\end{array}\right. \\
& f_{\text {site }}= \begin{cases}c_{10} \ln \left(\frac{V_{\mathrm{S} 30}}{k_{1}}\right)+k_{2}\left\{\ln \left[A_{1100}+c\left(\frac{V_{\mathrm{S} 30}}{k_{1}}\right)^{n}\right]-\ln \left(A_{1100}+c\right)\right\} & V_{\mathrm{S} 30}<k_{1} \\
\left(c_{10}+k_{2} n\right) \ln \left(\frac{V_{\mathrm{S} 30}}{k_{1}}\right) & k_{1} \leq V_{\mathrm{S} 30}<1100\end{cases} \\
& \left(c_{10}+k_{2} n\right) \ln \left(\frac{1100}{k_{1}}\right) \\
& 1100 \leq V_{\mathrm{S} 30} \\
& f_{\text {site }}\left(V_{\mathrm{S} 30}, T, y_{\text {ref }}\right)=\phi_{1}(T) \cdot \ln \left(\frac{V_{\mathrm{S} 30}}{1130}\right)+\phi_{2}(T) \cdot\left(\mathrm{e}^{\phi_{3}(T) \cdot\left[\min \left(V_{\mathrm{S} 30}, 1130\right)-360\right]}-\mathrm{e}^{\phi_{3}(T) \cdot(1130-36)}\right) \ln \left(\frac{y_{\text {ref }}(T)+\phi_{4}(T)}{\phi_{4}(T)}\right)
\end{aligned}
$$

\begin{tabular}{|c|c|c|c|c|c|c|}
\hline Earthquake name & a-mo-d & Magnitude & Lat. $/{ }^{\circ} \mathrm{N}$ & Long. $/{ }^{\circ} \mathrm{W}$ & Focal depth $/ \mathrm{km}$ & Sum of records \\
\hline Helena, Montana-01 & $1935-10-31$ & 6.00 & 46.61 & 111.96 & 6.00 & 1 \\
\hline Helena, Montana-02 & $1935-10-31$ & 6.00 & 46.62 & 111.97 & & 1 \\
\hline Hollister-03 & $1974-11-28$ & 5.14 & 36.92 & 121.47 & 6.11 & 1 \\
\hline Izmir, Turkey & $1977-12-16$ & 5.30 & 38.41 & $27.19 \mathrm{E}$ & 5.00 & 1 \\
\hline Santa Barbara & $1978-08-13$ & 5.92 & 34.40 & 119.68 & 12.70 & 1 \\
\hline Dursunbey, Turkey & 1979-07-18 & 5.34 & 39.66 & $28.65 \mathrm{E}$ & 7.00 & 1 \\
\hline Coyote Lake & 1979-08-06 & 5.74 & 37.08 & $121.51 \mathrm{E}$ & 9.60 & 3 \\
\hline Norcia, Italy & 1979-09-19 & 5.90 & 42.73 & $12.96 \mathrm{E}$ & 6.00 & 1 \\
\hline Livermore-02 & $1980-01-27$ & 5.42 & 37.74 & $121.74 \mathrm{E}$ & 14.50 & 1 \\
\hline Anza (Horse Canyon)-01 & $1980-02-25$ & 5.19 & 33.51 & $116.51 \mathrm{E}$ & 13.60 & 1 \\
\hline Mammoth Lakes-01 & $1980-05-25$ & 6.06 & 37.61 & 118.85 & 9.00 & 1 \\
\hline Mammoth Lakes-02 & $1980-05-25$ & 5.69 & 37.63 & 118.93 & 14.00 & 2 \\
\hline Mammoth Lakes-03 & $1980-05-25$ & 5.91 & 37.56 & 118.83 & 16.00 & 1 \\
\hline Mammoth Lakes-04 & $1980-05-25$ & 5.70 & 37.63 & 118.86 & 5.00 & 1 \\
\hline Mammoth Lakes-05 & $1980-05-26$ & 5.70 & 37.54 & 118.89 & 4.70 & 1 \\
\hline Mammoth Lakes-08 & $1980-05-31$ & 4.80 & 37.60 & 118.79 & 6.00 & 7 \\
\hline Mammoth Lakes-09 & 1980-06-11 & 4.85 & 37.55 & 118.88 & 7.63 & 6 \\
\hline Mammoth Lakes-10 & 1983-01-07 & 5.34 & 37.63 & 118.93 & 3.00 & 1 \\
\hline Mammoth Lakes-11 & 1983-01-07 & 5.31 & 37.63 & 118.94 & 4.50 & 1 \\
\hline Coalinga-02 & 1983-05-09 & 5.09 & 36.25 & 120.30 & 12.00 & 9 \\
\hline Coalinga-04 & 1983-07-09 & 5.18 & 36.25 & 120.40 & 9.00 & 7 \\
\hline Coalinga-05 & $1983-07-22$ & 5.77 & 36.24 & 120.41 & 7.40 & 5 \\
\hline Coalinga-06 & $1983-07-22$ & 4.89 & 36.22 & 120.41 & 7.90 & 1 \\
\hline N. Palm Springs & 1986-07-08 & 6.06 & 34.00 & 116.61 & 11.00 & 2 \\
\hline Kalamata, Greece-01 & $1986-09-13$ & 6.20 & 37.10 & $22.19 \mathrm{E}$ & 5.00 & 1 \\
\hline Kalamata, Greece-02 & $1986-09-15$ & 5.40 & 37.08 & $22.07 \mathrm{E}$ & 5.00 & 2 \\
\hline San Salvador & $1986-10-10$ & 5.80 & 13.63 & 89.20 & 10.90 & 2 \\
\hline Whittier Narrows-01 & 1987-10-01 & 5.99 & 34.05 & 118.08 & 14.60 & 7 \\
\hline Whittier Narrows- 02 & $1987-10-04$ & 5.27 & 34.06 & 118.10 & 13.30 & 3 \\
\hline Stone Canyon & 1972-09-04 & 4.81 & 36.57 & 121.30 & 8.00 & 1 \\
\hline Sierra Madre & 1991-06-28 & 5.61 & 34.26 & 118.00 & 12.00 & 1 \\
\hline Northridge-06 & 1994-03-20 & 5.28 & 34.23 & 118.48 & 13.09 & 5 \\
\hline San Juan Bautista & 1998-08-12 & 5.17 & 36.75 & 121.46 & 9.13 & 1 \\
\hline Gilroy & $2002-05-14$ & 4.90 & 36.97 & 121.60 & 10.12 & 2 \\
\hline Chi-Chi, Taiwan-02 & 1999-09-20 & 5.90 & 23.94 & $121.01 \mathrm{E}$ & 8.00 & 1 \\
\hline Chi-Chi, Taiwan-03 & 1999-09-20 & 6.20 & 23.81 & $120.85 \mathrm{E}$ & 8.00 & 3 \\
\hline
\end{tabular}

Table 1 Catalogue of small and moderate earthquakes used in this paper 
The coefficients of equations (3a) to (3d) are given in relevant references (Abrahamson and Silva, 2008; Boore and Atkinson, 2008; Campbell and Bozorgnia, 2008; Chiou and Youngs, 2008) respectively.

In this paper, the records in the epicentral distance less than $10 \mathrm{~km}$ are selected from the total records of M4.75-6.25 earthquakes in the NGA strong earthquake database for the statistic analysis to determine the ground motion acceleration spectra of diffuse earthquakes in the three different magnitude grades (Figure 1 and Table 1). The ground motion acceleration records on the site of $V_{\mathrm{S} 30}<700 \mathrm{~m} / \mathrm{s}$ are transformed into the ground motion acceleration records on the site of $V_{\mathrm{S} 30}=700 \mathrm{~m} / \mathrm{s}$ by the method in the NGA attenuation relationships.

\section{Statistic results of peak ground mo- tion acceleration}

On the basis of the sample selection principles and processing method determined in the above two sections, the average peak ground motion accelerations in near field for the three magnitude grades are obtained from the statistic analysis. Table 2 provides the sample means after the correction of PGA records is made by four correction models for the site condition. If the final means of $0.15 \mathrm{~g}, 0.20 \mathrm{~g}$ and $0.28 \mathrm{~g}$ are used as the peak near-source ground motion acceleration values for the M5.0, M5.5 and M6.0 earthquakes, respectively, its approximate logarithmic-linear relationship with the magnitude would coincide with the self-similarity characteristics between the high-frequency ground motion and the magnitude of about $M<7$ earthquakes (Hanks and Bakun, 2002; Halldorsson and Papageorgiou, 2005).

Using the five attenuation relationship models (AS08, BA08, CB08, CY08 and I08) developed in the NGA project, the near-source peak ground motion acceleration of earthquakes in three different rupture patterns (I08 model does not consider the difference in fault style) are calculated respectively for the magnitude grades of 5.0, 5.5 and 6.0 (see Table 3). In the calculation, the shortest horizontal distance (Joyner-Boore distance, $R_{\mathrm{JB}}$ ) from the recording site to the vertical projection of the rupture is approximately taken as the epicentral distance of $R_{\mathrm{JB}}=5 \mathrm{~km}$, which is used as the near-source ground motion comparable to the statistic range in this paper. At the same time, in considering the mean focal depth and the source dimension of small and moderate earthquakes, the depth to top of fault rupture model is taken as $Z_{\mathrm{TOR}}=5 \mathrm{~km}$, the closest distance from recording site to the rupture area of seismogenic fault is $R_{\mathrm{RUP}}=\sqrt{R_{\mathrm{JB}}^{2}+Z_{\mathrm{TOR}}^{2}}=7.1 \mathrm{~km}$, and the site condition is $V_{\mathrm{S} 30}=700 \mathrm{~m} / \mathrm{s}$. The above hypothesis could represent the general case in the ground motion analysis of small and moderate earthquakes. The column "Aver. 1" in Table 3 denotes the mean calculated result of five attenuation models in the condition with the same magnitude and the same fault style, while the column "Aver. 2" indicates the averaged result of five attenuation models with the same magnitude and non-distinguished fault style. We have discovered that, from the comparison of the statistic result in this paper (Table 2) with the computed

Table 2 Statistics results of near-source PGA of small earthquakes after the NGA correction for site condition

\begin{tabular}{cccccr}
\hline \multirow{2}{*}{ Magnitude } & \multicolumn{3}{c}{ PGA/g } & \multicolumn{2}{c}{ Average PGA/g } \\
\cline { 2 - 5 } & AS08s & BA08s & CB08s & CY08s & 0.15 \\
$4.75-5.25$ & 0.149 & 0.130 & 0.159 & 0.143 & 36 \\
$5.25-5.75$ & 0.209 & 0.183 & 0.221 & 0.197 & 0.20 \\
$5.75-6.25$ & 0.300 & 0.251 & 0.319 & 0.277 & 0.28 \\
\hline
\end{tabular}

Table 3 Near-source ground motion calculated by NGA attenuation relationships

\begin{tabular}{|c|c|c|c|c|c|c|c|c|}
\hline \multirow{2}{*}{ Magnitude } & \multirow{2}{*}{ Fault style } & \multicolumn{5}{|c|}{$\mathrm{PGA} / \mathrm{g}$} & \multirow{2}{*}{ Aver. 1} & \multirow{2}{*}{ Aver. 2} \\
\hline & & AS08 & BA08 & CB08 & CY08 & I08 & & \\
\hline \multirow{3}{*}{5.0} & Normal & 0.161 & 0.076 & 0.125 & 0.125 & 0.127 & 0.12 & \multirow{3}{*}{0.14} \\
\hline & Reverse & 0.171 & 0.097 & 0.184 & 0.178 & 0.127 & 0.15 & \\
\hline & Strike & 0.171 & 0.098 & 0.140 & 0.161 & 0.127 & 0.14 & \\
\hline \multirow{3}{*}{5.5} & Normal & 0.213 & 0.113 & 0.191 & 0.177 & 0.166 & 0.17 & \multirow{3}{*}{0.20} \\
\hline & Reverse & 0.226 & 0.144 & 0.282 & 0.251 & 0.166 & 0.21 & \\
\hline & Strike & 0.226 & 0.144 & 0.215 & 0.228 & 0.166 & 0.20 & \\
\hline \multirow{3}{*}{6.0} & Normal & 0.276 & 0.158 & 0.226 & 0.230 & 0.218 & 0.22 & \multirow{3}{*}{0.25} \\
\hline & Reverse & 0.293 & 0.202 & 0.333 & 0.326 & 0.218 & 0.27 & \\
\hline & Strike & 0.293 & 0.203 & 0.254 & 0.296 & 0.218 & 0.25 & \\
\hline
\end{tabular}

Note: The column "Aver. 1" denotes the averaged calculated result of five attenuation models in the condition with the same magnitude and the same fault style, while "Aver. 2 " indicates the averaged result of five attenuation models in the condition with the same magnitude and non-distinguished fault style. 
results by the NGA attenuation relationship, the former is larger than the latter for the 6.0 magnitude grade. The two groups of peak ground motion acceleration are basically consistent for the 5.0 and 5.5 magnitude grades.

In the past several years, many researches were also made in the near-source ground motion attenuation law of small earthquakes in China. The most representative ones are accomplished by Jin and Yu (2009) and Wang (2002), whose attenuation relationship models are noted as JY09 and W02. The attenuation relationship models in both researches are consistent, in which the focal length is taken as the distance scale. For the general case of focal depth of small and moderate earthquakes, the condition with the focal length of $10 \mathrm{~km}$ corresponds basically to the statistic range in this paper. The near-source peak ground motion accelerations for 5.0, 5.5 and 6.0 earthquakes are calculated and the results are shown in Table 4. In the comparison with the statistic result in this paper, the computed results from the above two researches are smaller, especially the result of W02.

Table 4 Near-source ground motion calculated by JY09 and W02

\begin{tabular}{ccc}
\hline Magnitude & PGA from JY09/g & PGA from W02/g \\
\hline 5.0 & 0.14 & 0.069 \\
5.5 & 0.19 & 0.12 \\
6.0 & 0.24 & 0.20 \\
\hline
\end{tabular}

Comparing the two kinds of results, we have discovered that the result in this paper is generally larger than the results calculated by the attenuation relationship models. It is possibly because that the near-source records of small and moderate earthquakes are directly used in the statistics in this paper, while the results from the above several attenuation relationship models are obtained by regression analysis based on the records of different magnitudes and different distances, which is somewhat an average quantity affected inevitably by the ground motion characteristics of other magnitudes and other epicentral distances in certain respects. In this aspect, the statistic result in this paper might better reflect the near-source ground motion characteristics of small and moderate earthquakes, which indicates that, if this conjecture is reasonable, it is more rational to determine the ground motion influence of diffuse earthquake on the nuclear facility site directly from the near-source records of small and moderate earthquakes. Therefore, the values of $0.15 \mathrm{~g}, 0.20 \mathrm{~g}$ and $0.28 \mathrm{~g}$ acquired in this study can be used as a basis to determine peak ground motion acceleration of M5.0, M5.5 and M6.0 diffuse earthquakes on the nuclear facility site.

\section{Statistic results of ground motion ac- celeration spectra}

Using the ground motion record samples selected in above section, the average ground motion acceleration spectra in the near field for the three magnitude grades are obtained from the statistic analysis (see Table 5).

Table 5 Statistics results of near-source acceleration spectra of small earthquakes after the NGA correction for site condition

\begin{tabular}{clll}
\hline \multirow{2}{*}{$\begin{array}{c}\text { Period } \\
\mathrm{s}\end{array}$} & \multicolumn{3}{c}{ Spectrum acceleration $/ \mathrm{g}$} \\
\cline { 2 - 4 } 0.03 & 0.16 & 0.21 & $M 6.0$ \\
\hline .05 & 0.21 & 0.25 & 0.29 \\
0.07 & 0.28 & 0.31 & 0.33 \\
0.10 & 0.31 & 0.34 & 0.42 \\
0.15 & 0.33 & 0.44 & 0.48 \\
0.20 & 0.28 & 0.42 & 0.54 \\
0.30 & 0.18 & 0.40 & 0.59 \\
0.40 & 0.13 & 0.30 & 0.49 \\
0.50 & 0.080 & 0.23 & 0.39 \\
0.75 & 0.036 & 0.14 & 0.35 \\
1.00 & 0.022 & 0.088 & 0.28 \\
1.50 & 0.0084 & 0.037 & 0.16 \\
2.00 & 0.0045 & 0.020 & 0.084 \\
3.00 & 0.0018 & 0.0078 & 0.053 \\
4.00 & 0.0010 & 0.0038 & 0.021 \\
\hline
\end{tabular}

\section{Discussion and conclusions}

On the basis of the near-source saturation characteristics of ground motion, the mean statistic value of near-source peak ground motion acceleration and acceleration spectra within a certain epicentral distance is used as the ground motion influence of diffuse earthquake on the nuclear facility site. To increase the capacity of statistic samples, ground motion records on the soil sites are transformed into the equivalents for the site of $V_{\mathrm{S} 30}=700 \mathrm{~m} / \mathrm{s}$ according to the site correction term in the NGA attenuation relationship for a simultaneous statistic analysis with the bedrock $\left(V_{\mathrm{S} 30} \geq 700 \mathrm{~m} / \mathrm{s}\right)$ records. The objective of this paper is to find a more reasonable method to determine the design basis ground motion of diffuse earthquake at the nuclear facility site. And the preliminary results listed in Table 2 and Table 5 can be used as a base of determination of design basis ground motion for nuclear facilities.

But there are some critical problems that need to be discussed. What we have done in this paper only proves the potential application of this method to practice and the possibility to transform the soil ground motion re- 
cords into the bedrock ones. The parameters and measures used in this paper are simplified to a considerable extent according to the above principles. However, further research is still needed for the following respects.

1) The determination of near-source saturation range of small and moderate earthquakes, that is to determine the distance zone for selecting near-source ground motion records. This is a key point to further research.

The distance of $10 \mathrm{~km}$ used uniformly in this paper is only a numerical value approximately determined by the empirical formula, in which the difference among earthquakes of different magnitudes is not distinguished. In further research, the data of small and moderate earthquakes relating directly to determination design basis ground motion of diffuse earthquakes should be used; the regional difference in ground motion characteristics of small and moderate earthquakes, as well as the focal mechanism and its effect on the near-source saturation features of small and moderate earthquakes should also be considered if necessary, in order to determine the distance range for selecting earthquake record samples more thoroughly and directly.

2) Are there any regional differences in the ground motion variation of small and moderate earthquakes and the characteristics of near-source ground motion? As to the ground motion records used in this paper, most of them are located in western America and a small amount of them are in western Asia and European area. Jin and $\mathrm{Yu}$ (2009) mentioned above indicates that it seems there is certain systematic difference between the small and moderate earthquakes occurred in Europe and those in western America. How to consider this kind of difference in the research on the ground motion characteristics of small and moderate earthquakes in China? It is really a subject that should be studied on the basis of more extensive data.

3) The site correction method used in this paper is determined on the basis of statistic analysis of ground motion records of different magnitudes and distances in the NGA project with an auxiliary measure of numerical simulation. However, most of the records they used are not included in the interested scope of this article, so it might be possible that the soil response feature of nearsource ground motion on the soil site is inaccurately reflected. Therefore, we should make a detailed analysis on the ground motion soil response for the near-source ground motion records of small earthquakes used in this paper, in which a reasonable model for analyzing soil response is needed. This is an important fundamental work for the whole research.

Acknowledgements This study is supported by the Special Funds for Sciences and Technology Research (No. 200708003 and No. 200808008) and National Natural Science Foundation of China (No. 90715020). Contribution No. is 10FE3001, Institute of Geophysics, China Earthquake Administration.

\section{References}

Abrahamson N and Silva W (2008). Summary of the Abrahamson \& Silva NGA ground-motion relations. Earthq Spectra 24: 67-97.

Boore D M and Atkinson G M (2008). Ground-motion prediction equations for the average horizontal component of PGA, PGV, and 5\%-damped PSA at spectral periods between $0.01 \mathrm{~s}$ and $10.0 \mathrm{~s}$. Earthq Spectra 24: 99-138.

Campbell K W (1981). Near-source attenuation of peak horizontal acceleration. Bull Seism Soc Amer 71: 2 039-2 070.

Campbell K W and Bozorgnia Y (2008). NGA ground motion model for the geometric mean horizontal component of PGA, PGV, PGD, and 5\% damped linear elastic response spectra for period ranging from 0.01 to $10 \mathrm{~s}$ Earthq Spectra 24: 139-171.

Chiou B and Youngs R (2008). An NGA model for the average horizontal component of peak ground motion and response spectra. Earthq Spectra 24: 173-215.

Chiou B, Power M, Abrahamson N and Roblee C (2006). An overview of the project of next generation of ground motion attenuation models for shallow crustal earthquakes in active tectonic regions. Proceedings of Fifth National Seismic Conference on Bridges \& Highways. San Francisco, USA, 18-20 September 2006, Paper No. B11.

Halldorsson B and Papgeorgiou A S (2005). Calibration of the specific barrier model to earthquakes of different tectonic regions. Bull Seism Soc Amer 95: $1276-1300$.

Hanks T C and Bakun W H (2002). A bilinear source-scaling model for $M-\log A$ observations of continental earthquakes. Bull Seism Soc Amer 92: $1841-1846$.

Huo J R (1989). Research on the Attenuation Law of Near-Source Ground Movement. PhD Dissertation, Institute of Engineering Mechanics, China Earthquake Administration, Harbin, 89-138 (in Chinese with English abstract).

Idriss I M (2008). An NGA empirical model for estimating the horizontal spectral values generated by shallow crustal earthquakes. Earthq Spectra 24: 217-242.

Jin C Y and Yu Y X (2009). Attenuation relationships for horizontal ground motion on rock of small-moderate earthquakes in Europe. Earthquake Research in China 25(2): 170-177 (in Chinese with English abstract).

Li X J, Yan X J and Pan H (2005). Suitability analysis of ground motion attenuation relation in estimation of near-field ground motion for small and moderate earthquakes. Earthq Eng Eng Vib 25(1): 1-7 (in Chinese with English abstract).

Schmedes J and Archuleta R J (2008). Near-source ground motion along strike-slip faults: insights into magnitude saturation of PGV and PGA. Bull Seism Soc Amer 98: 2278-2 290.

Wang H J (2002). Strong Ground Motion Attenuation Relationship of Small-Moderate Earthquakes. Master Dissertation, Institute of Geophysics, China Earthquake Administration, Beijing, 31-43 (in Chinese with English abstract).

Yu Y X (2002). Study on Attenuation Relationships of Long Period Ground motions. PhD Dissertation, Institute of Geophysics, China Earthquake Administration, Beijing, 94-120 (in Chinese with English abstract).

Zhang Y J, Wu Z L and Jiang C S (2004). Scaling of source parameters from the digital imaging of earthquake rupture process. Earthquake Research in China 20(4): 330-340 (in Chinese with English abstract). 